\title{
Diamond Deposition on Graphite in Hydrogen Microwave Plasma
}

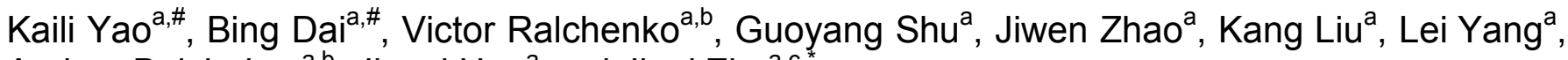 \\ Andrey Bolshakov ${ }^{\mathrm{a}, \mathrm{b}}$, Jiecai $\mathrm{Han}^{\mathrm{a}}$ and Jiaqi Zhu ${ }^{\mathrm{a}, \mathrm{c},{ }^{*}}$ \\ ${ }^{a}$ Center for Composite Materials and Structures, Harbin Institute of Technology, Harbin, 150080, P. R. China \\ ${ }^{b}$ General Physics Institute of Russian Academy of Sciences, RAS, Vavilov str. 38, Moscow 119991, Russia
}

${ }^{C}$ Key Laboratory of Micro-systems and Micro-structures Manufacturing, Ministry of Education, Harbin Institute of Technology, Harbin, 150080, P. R. China

\begin{abstract}
Hydrogen plasma etching of graphite generates radicals that can be used for diamond synthesis by chemical vapor deposition (CVD). We studied the etching of polycrystalline graphite by a hydrogen microwave plasma, growth of diamond particles of the non-seeded graphite substrates, and characterized the diamond morphology, grain size distribution, growth rate, and phase purity. The graphite substrates served simultaneously as a carbon source, this being the specific feature of the process. A disorder of the graphite surface structure reduces as the result of the etching as revealed with Raman spectroscopy. The diamond growth rate of $3-5 \mu \mathrm{m} / \mathrm{h}$ was achieved, the quality of the produced diamond grains improving with growth time due to inherently nonstationary graphite etching process.
\end{abstract}

Received on 29-12-2017

Accepted on 05-03-2018

Published on 16-08-2018

Keywords: Microwave plasma, diamond deposition, hydrogen plasma, graphite, etching.

\section{INTRODUCTION}

Diamond films and particles produced by chemical vapor deposition (CVD) find many applications in electronics, photonics, quantum informatics, thermal management, tribology due to a combination of extreme physical properties of this material, such as high thermal conductivity, wide optical transparence spectral window, high mobility of charge carriers, low friction coefficient and biocompatibility [1-10].

As an alternative, some groups have demonstrated the diamond film prepared via hydrogen plasma etching of graphite to form $\mathrm{CH}_{\mathrm{x}}$ radicals necessary for the diamond growth [5-16]. Salvadori et al. [17] described growing diamond film using a graphite plate exposed to the microwave hydrogen plasma along with a separate substrate on which the diamond film was deposited, and compared the morphology and quality of the diamond films formed under hydrogen pressures of 80 to 140 Torr. Lu et al. [14] investigated how the hydrogen flow rate affected the growth rate and morphology of diamond with graphite etching and found that the growth rate and nucleation density of diamond

"Center for Composite Materials and Structures, Harbin Institute of Technology, Harbin, 150080, P. R. China; Tel: 86-451-86402954; Fax: 86-451-86403218; E-mail: zhujq@hit.edu.cn

"These two authors contributed equally to this work. films increased significantly with the decrease of hydrogen flow rate. Silva et al. [15] prepared diamond films from graphite at different temperatures instead of utilizing conventional hydrocarbon in the feed gas. The diamond nucleation and growth rate showed a strong dependence on the graphite temperature, with higher quality and growth rate at higher temperatures. However, most works focused on the analysis of the produced diamond film with a less attention to study of the etched graphite properties, such as the morphology and disorder level. As a rare exclusion, Silva et al. [15] analyzed the graphite structure after etching process with Raman spectroscopy and found that the graphite disorder increased monotonously with the graphite temperature. However, they did not investigate the diamond growth on the graphite itself.

The use of solid carbon source has been proved to have distinct advantages over the gas carbon source, such as a high carbon concentration provided by etched graphite sheets around the substrate and a lower substrate temperature, down to $250{ }^{\circ} \mathrm{C}$ [13], which is beneficial for some materials with low melting point [11-17]. Besides, the graphite sheets as the substrate can make the synthesized diamond powders easily removed from the substrate, due to low adhesion [18]. 
In the present work, we studied the etching of the graphite sheets by hydrogen microwave plasma to produce CVD diamond particles. A special feature of the process was the use of etched graphite simultaneously as the substrate for diamond deposition. The morphology and disorder level of graphite, as well as the diamond growth rate and purity evolution with prolonging etching time were examined.

\section{EXPERIMENTAL}

Prior to the etching experiment, a graphite plate (Hatan Co.) with the size of $30 \times 30 \times 1.8 \mathrm{~mm}$ and purity of $99.9 \%$ was cleaned with acetone and ethanol for $30 \mathrm{~min}$, separately, then dried in a vacuum oven at $80^{\circ} \mathrm{C}$. At the next stage, the graphite plate was put on a molybdenum substrate holder in the microwave plasma CVD reaction chamber (MPCVD) to serve as both a carbon source and the substrate. The graphite sheet was etched in the MPCVD reactor PLASSYS SSDR150 operated at frequency of $2.45 \mathrm{GHz}$, in pure hydrogen $(99.999 \%)$ feed gas under the following process parameters: $\mathrm{H}_{2}$ flow rate of $200 \mathrm{sccm}$, the substrate temperature of $900^{\circ} \mathrm{C}$ as measured with a pyrometer (Williamson PRO 92-40-C), incident microwave power of $3050 \mathrm{~W}$, pressure of $180 \mathrm{mbar}$, the process time of $1 \mathrm{~h}, 3 \mathrm{~h}, 8 \mathrm{~h}$ and $13 \mathrm{~h}$.

After the etching/growth process, the grown diamond powders were collected from the graphite sheet. Those diamond particles were typically agglomerates of smaller diamond grains, formed due to an incessant re-nucleation [19]. Therefore to separate the aggregated particles to individual grains they were ground for $30 \mathrm{~min}$ in a stainless steel mortar, followed by ultrasonically cleaning with acetone and alcohol [20]. Only the diamond particles grown after 3h, $8 \mathrm{~h}$ and $13 \mathrm{~h}$ were collected and treated, whereas the fine powder grown after $1 \mathrm{~h}$ graphite etching was difficult to collect.

The morphologies of the etched graphite and the produced diamond particles were examined with a field emission scanning electron microscopy (FE-SEM) (Helios Nanolab $600 i)$. The graphite structure disorder, as well as the quality and purity of the deposited diamond particles obtained from different etching durations, were assessed with Raman spectroscopy (Renishaw inVia system) operated at $532 \mathrm{~nm}$ excitation wavelength, with laser beam diameter of $\sim 1 \mu \mathrm{m}$ on the sample surface. Here, the terms "quality and purity" signify the presence of $\mathrm{sp}^{2}$-bonded (graphitic-like) carbon versus diamond phase (the lower $\mathrm{sp}^{2}$ carbon content means better quality). The mean size of the diamond grains after deagglomeration was measured with Mastersizer 3000 laser diffraction particle size analyzer (Malvern Instruments, China), by immersing the powders in deionized water.

\section{RESULTS AND DISCUSSION}

Figure 1 depicts the SEM images of the as-grown diamond powders on the etched graphite and the surface of etched graphite sheets after removing the diamond powders for different etching durations.
The degree of the grown diamond agglomeration highly depends on the etching time. Well-faced isolated diamond particles with the size of about $3 \mu \mathrm{m}$ are observed after $1 \mathrm{~h}$ growth (Figure 1a, b). However, more and more diamond particles agglomerate with a longer etching time, and the size of agglomerates increases up to $\approx 400 \mu \mathrm{m}$, as shown in Figure 1e. This may indicate that the agglomerative diamonds are the result of incessant re-nucleation process [19]. The repeated nucleation is generated on the original particles with time, leading to an aggregate structure. The size of the diamond grain with the agglomerates also increase with process time. The specific diamond grain size distributions after de-aggregation [20] were characterized by laser granular analyzer and the result is presented in Figure 3a, b.

Because of the low adhesion of the deposited grit to the substrate, the diamond was easily collected. Figure 1d, f, depicts the surface of graphite sheets after removing the diamond particles produced for $3 \mathrm{~h}, 8 \mathrm{~h}$. The etched graphite reveals a more rough surface with many holes and cavities, compared with the virgin graphite sheet (Figure 1h). Some residual diamond particles with small, few microns only, grain size on the graphite surface still present after "harvesting" of the larger particles (compare Figure 1c and $\mathbf{d}$, e and f. Those fine particles (demonstrated at higher magnification in Figure 1g) began to form in a later period of the etching/growth process, confirming the continuous nucleation model. The CVD diamond particles spontaneously nucleate and grow heteroepitaxially preferentially on damaged prism planes of graphite [21, 22], so the diamond growth proceeds without any pre-treatment of the graphite substrate. The nucleation density, therefore, increases with the number of open edges of graphite planes, while a rear nucleation is expected for highly ordered graphite with basal planes parallel to the substrate surface. The complicated surface relief of the graphite, as seen in Figure 1, facilitated the diamond growth in the present experiment.

The diamond powders and the graphite sheets were separated and were then used for characterization. Raman spectra of the polycrystalline graphite sheets taken before and after the etching are shown in Figure 2a. The curve at $t=$ Oh in Figure 2a means the Raman spectrum for the graphite piece before etching. Three graphite peaks: $D$ band (1350 $\left.\mathrm{cm}^{-1}\right), \mathrm{G}$ band $\left(1580 \mathrm{~cm}^{-1}\right)$ and $\mathrm{G}^{\prime}$ band $\left(2700 \mathrm{~cm}^{-1}\right)$ dominate the spectra. The $\mathrm{G}$ band is related to phonon vibrations in $\mathrm{sp}^{2}$ carbon materials, while the $\mathrm{D}$ band is ascribed to disordered carbon, edge defects, and other defects [23]. The high frequency shoulder of the $G$ peak at $1620 \mathrm{~cm}^{-1}$ is the D' peak, which is the defect induced Raman feature as well as the $D$ peak, and thus these bands cannot be seen for a highly ordered graphite [24]. The Raman feature at about $2950 \mathrm{~cm}^{-1}$ is associated with a $D+G$ combination mode and also is induced by disorder [24]. The strong peak and minor peak at $\sim 2400 \mathrm{~cm}^{-1}$ belong to the $2^{\text {nd }}$ order spectrum of graphite, the $G$ ' frequency being almost doubled to that of $D$ peak (see more in Ref. [25]). 



Figure 1: SEM images of diamond grown particles and aggregates on graphite (left panels) and the surface of etched graphite sheets, where some diamond particles are still residual after collecting diamond (right panels) after $1 \mathrm{~h} \mathrm{(a),} \mathrm{(b);} 3 \mathrm{~h} \mathrm{(c),} \mathrm{(d);} \mathrm{and} 8 \mathrm{~h}(\mathbf{e}),(\mathbf{f})$ at $900{ }^{\circ} \mathrm{C}$. The faceted diamond particles found after $13 \mathrm{~h}$ growth (Figure 1g). The surface of virgin graphite is displayed in Figure $\mathbf{1 h}$.

Both the ratio intensity $I_{D} / I_{G}$ for the $D$ and $G$ bands, and the $G$ bandwidth $\Delta \mathrm{v}_{\mathrm{G}}$, (full width at half maximum - FWHM), which indicate a disorder degree of the graphite structure, are displayed in Figure 2b, c for different etch times. Each sample was measured in three different locations to reduce the error. The pristine graphite reveals a high disorder level, with the average values of $\mathrm{I}_{\mathrm{D}} / \mathrm{l}_{\mathrm{G}} \approx 0.53$ and $\Delta \mathrm{v}_{\mathrm{G}} \approx 33 \mathrm{~cm}^{-1}$. By comparison, the average values $I_{D} / l_{G}$ and $\Delta v_{G}$ reduce down to
0.32 , and $24 \mathrm{~cm}^{-1}$, respectively, after $1 \mathrm{~h}$ etching, and keep stable around 0.22 , and $19 \mathrm{~cm}^{-1}$ for the longer etching till $13 \mathrm{~h}$, hence, the graphite disorder level decreases after etching. We ascribe this structure improvement to removal of a surface damaged layer formed upon the graphite sheets fabrication by mechanical cutting of primary graphite thick slabs, and to enhanced selective etching by hydrogen of most defected parts of the pristine bulk graphite structure. 

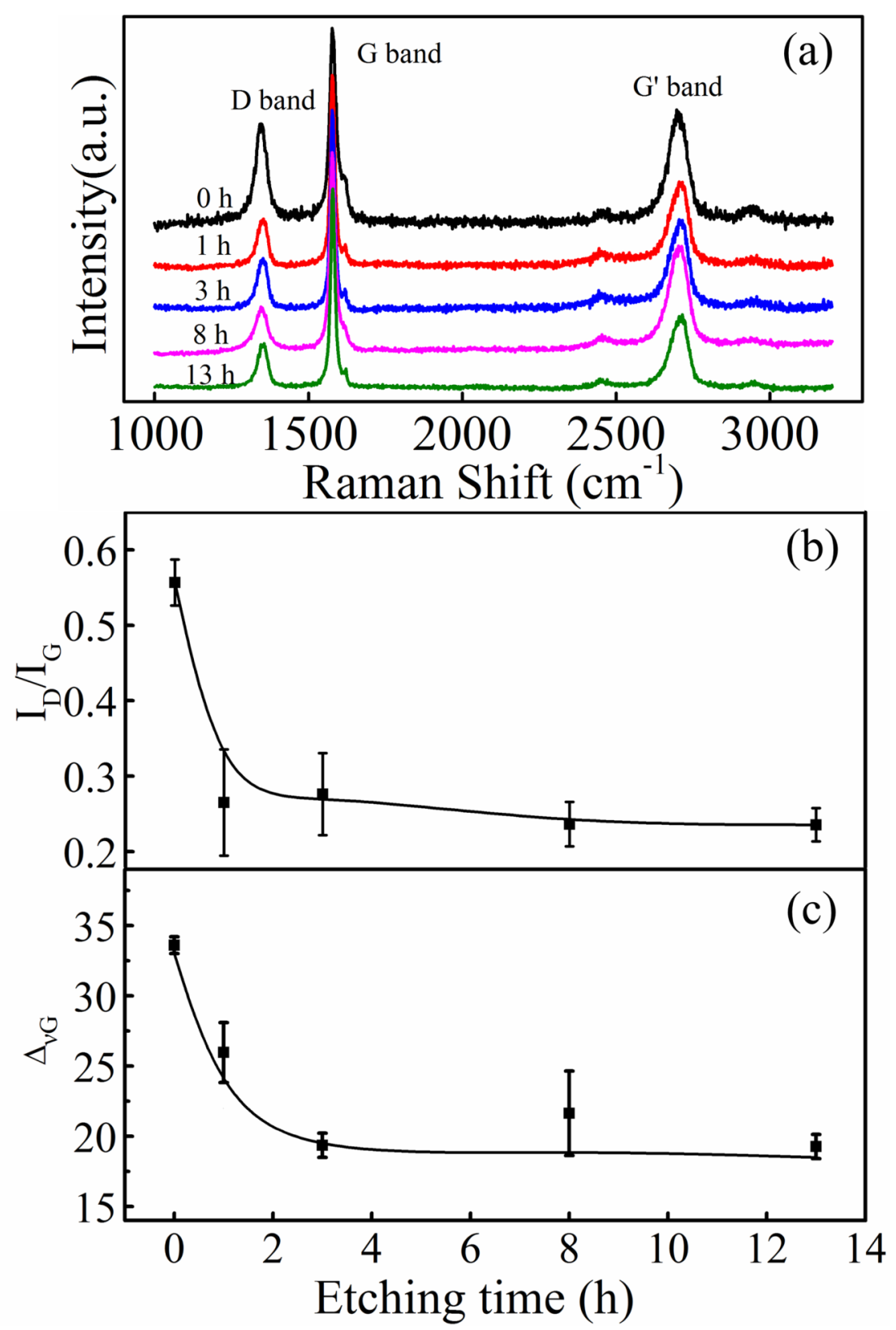

Figure 2: Raman spectra, from top to bottom, of graphite sheet etched at $900{ }^{\circ} \mathrm{C}$ for $0 \mathrm{~h}, 1 \mathrm{~h}, 3 \mathrm{~h}, 8 \mathrm{~h}$ and $13 \mathrm{~h}$, taken after removal of diamond particles (a); the intensity ratio $I_{D} / l_{G}$ of $D$ and $G$ bands (b) and width (FWHM) $\Delta v G$ of $G$ band $(\mathbf{c})$ as a function of etching duration. The error bars are calculated from the data scattering over measurements at three different locations. The lines are guides for eyes.

In addition, the studies on diamond collected from the graphite substrate were carried out. The dispersed diamond grits after mechanical chipping exhibited irregular shapes and sizes, varied from large complex particles, not split completely, to a fine grit fraction. Therefore we measured the specific range of diamond grain size for all samples and obtained average grain size. The size distributions for a growth time of $3 \mathrm{~h}, 8 \mathrm{~h}$, and $13 \mathrm{~h}$ are displayed in Figure $\mathbf{3 a}, \mathbf{b}$. With longer etch time from $3 \mathrm{~h}$ to $13 \mathrm{~h}$, the peak volume ratio of diamond particle size moves to the right, meaning bigger diamond grain size, as expected.

The diamond particles exhibit multiple twins and dominating triangular (111) facets and many pyramidal features with sharp tips (Figure 1h), which is favorable for abrasive applications [26], particularly grinding and polishing of ceramics, hard non-ferrous alloys, composite materials essentially are based on the use of the diamond powders as superabrasives. The grit size increases with the etching time, as shown in SEM images in the inset in Figure 3c. The specific average diamond particle sizes measured are shown in Figure 3c. The average dispersed grain size grown for $1 \mathrm{~h}$ was obtained from SEM, as exhibited in Figure 1a, b. The other three diamond particle size results were measured with the laser granularity analyzer.

The diamond grain size $R$ increases monotonically to $15 \mu \mathrm{m}$ for the first three hours, and up to $34 \mu \mathrm{m}$ after $13 \mathrm{~h}$ of the 

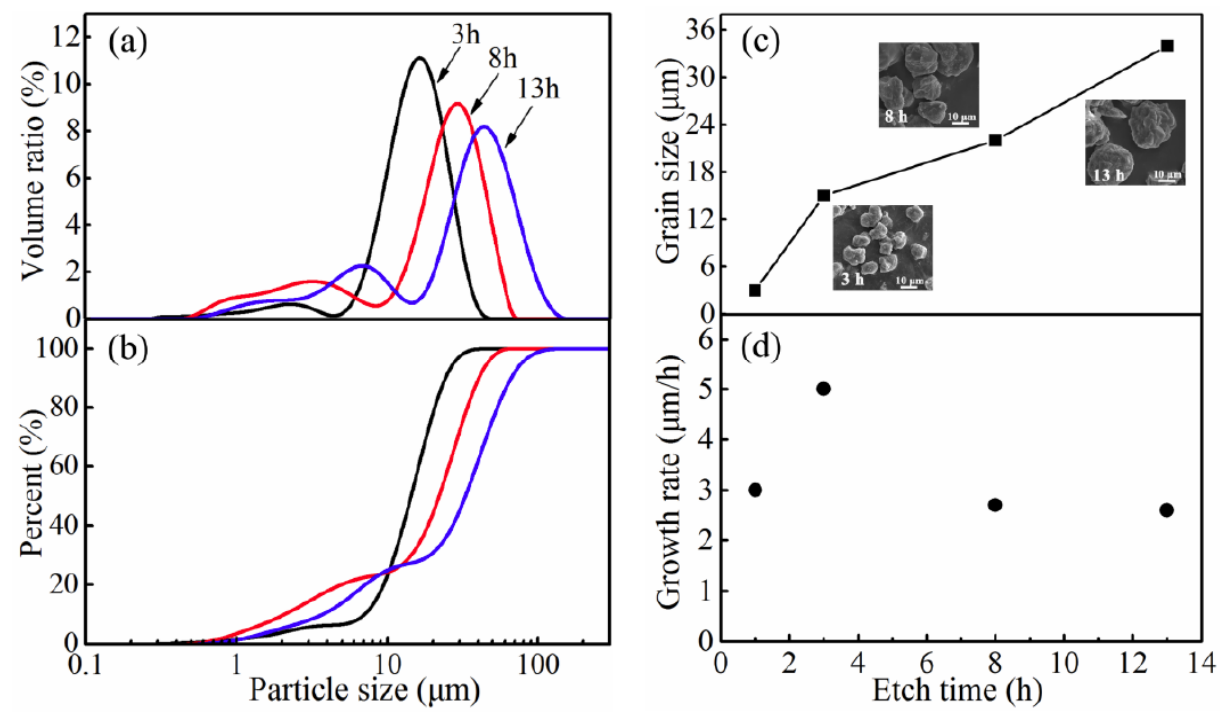

Figure 3: (a) De-agglomerated diamond grain size distribution (top) and (b) percentage of all particles with size below the given one (bottom) for samples produced with etching durations of $3 \mathrm{~h}$ (black curves), $8 \mathrm{~h}$ (red curves) and $13 \mathrm{~h}$ (blue curves); (c) the average diamond particle size and (d) average growth rate versus etching time. Inset: SEM images of the diamond grit for different growth times, taken at the same magnification.

growth process (see Figure 3c). The growth rate $G R(t)=R / t$ here is the average of an instantaneous growth rate over the time interval $t$. The diamond growth rate demonstrates some increase from 3 to $5 \mu \mathrm{m} / \mathrm{h}$ during the first three hours, and a further decrease and stabilization around $3 \mu \mathrm{m} / \mathrm{h}$ for a period of $8 \mathrm{~h}$ to $13 \mathrm{~h}$, as shown in Figure 3d. A possible reason for the observed decline in the growth rate could be a decrease in the flux of diamond precursors $\left(\mathrm{CH}_{\mathrm{x}}\right.$ radicals) with time, as the produced diamond particles covering a part of the graphite substrate surface.

Additionally, the structure of graphite becomes less disordered (Figure $\mathbf{2 b}, \mathbf{c}$ ), as the most defected surface layer was easily etched away by hydrogen plasma, even without any activation energy $[15,27]$. Therefore, the etching of the rest more ordered graphite and production of hydrocarbon radicals slow down, leading to a lowering the growth rate of diamond particles with time.

The Raman spectra of dispersed diamond particles produced for different growth durations are presented in Figure 4. The spectra reveal a sharp peak at $1332 \mathrm{~cm}^{-1}$ characteristic for diamond, and a broadband from $1450 \mathrm{~cm}^{-1}$ to $1600 \mathrm{~cm}^{-1}$, centered at $\approx 1550 \mathrm{~cm}^{-1}$, that is a superposition of the Gpeak $\left(\approx 1550 \mathrm{~cm}^{-1}\right)$ of graphitic structure and of $1480 \mathrm{~cm}^{-1}$ band of the trans-polyacetylene component on grain boundaries $[3,28]$. In addition, the peak intensity of nondiamond phases reduces with the growth time, indicating a lowering of concentration of the $\mathrm{sp}^{2}$-bonded carbon and higher quality of the produced diamond.

The inset in Figure 4 shows the change of the diamond peak width $\Delta v(F W H M)$ for the diamond samples. The $\Delta v$ value monotonously decreases with the growth time, from $15.1 \mathrm{~cm}^{-1}$ (after the $3 \mathrm{~h}$ process) to $11.2 \mathrm{~cm}^{-1}(13 \mathrm{~h})$, confirming a better quality of the diamond particles produced for longer etching/growth time (the smaller $\Delta v$ value indicates a higher crystalline quality and purity $[29,30])$.

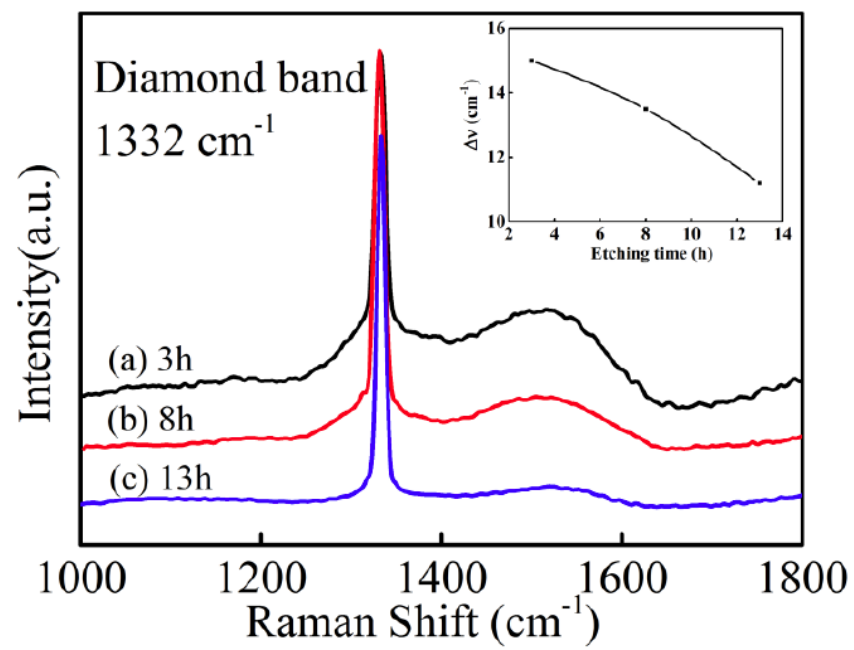

Figure 4: Raman spectra of diamond powder grown, from top to bottom, for $3 \mathrm{~h}, 8 \mathrm{~h}$, and $13 \mathrm{~h}$ at $900^{\circ} \mathrm{C}$. Inset: diamond peak width $\Delta \mathrm{v}$ (FWHM) versus etching time.

The growth process of the diamond particles prepared by hydrogen plasma etching graphite as the carbon source is schematically shown in Figure $\mathbf{5}$. The whole process can be divided into three steps. First, primary hydrocarbon radicals $\mathrm{CHx}$, are formed when the hydrogen plasma attacks the graphite substrate $[3,31,32]$. The diamond precursor, methyl $\mathrm{CH}_{3}$, and other carbon species, like $\mathrm{CH}, \mathrm{C}_{2}$ form in the plasma via reaction with hydrogen $\mathrm{H}, \mathrm{H}_{2}$, and other species, and the diamond nucleation on graphite surface then occurs [33]. At the last stage of the formation mechanism, diamond nuclei grow up to micro-size diamond particles on the graphite substrate. Due to the secondary nucleation on the original particles with time, an aggregate structure of diamond 


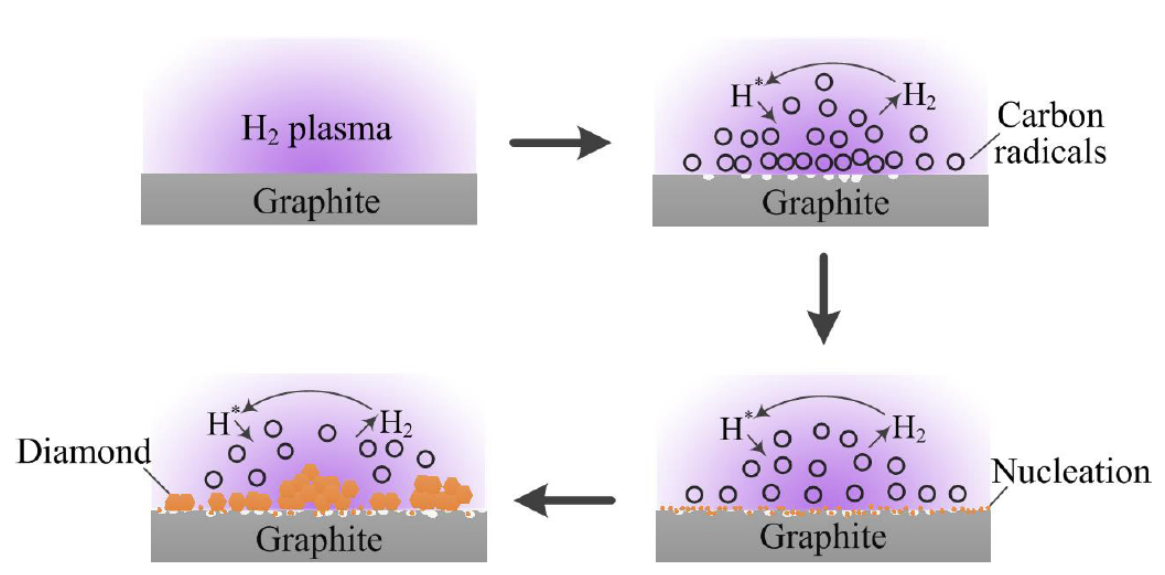

Figure 5: The schematics of diamond particles growth via hydrogen plasma etching of graphite.

is formed gradually (Figure 5). Additionally, the more diamond particles deposit on the graphite, the smaller is the graphite surface area remained open for hydrogen plasma etching, leading to fewer carbon radicals produced, and the less the $\mathrm{sp}^{2}$ amorphous carbon forms, thus improving the deposited diamond quality.

\section{CONCLUSIONS}

In summary, the effect of hydrogen microwave plasma etching of polycrystalline graphite in a CVD reactor and the diamond deposition on the graphite substrates, have been studied. Using Raman spectroscopy, the structural disorder of the graphite is found to reduce with the etching time, presumably due to selected enhanced etching of the most defected fragments of the graphite lattice. Simultaneously, diamond particles grow on the graphite substrate as a result of spontaneous nucleation (no seeding of the substrate with a nano-diamond grit or by other means was used). We monitored the evolution of the diamond particles with process time and characterized their morphology, grain size distribution, growth rate, and phase purity. The diamond growth on graphite is specific in comparison with other substrate materials, as the substrates area is shrinking in the course of the deposition because of a shielding effect of the produced diamond. This leads to a non-stationary flux of carbon to the plasma and gradual improvement of the diamond quality. The use of graphite as the solid carbon source can be used to deposit continuous diamond films on separate non-carbon substrates [11-16], while such films on graphite could be grown using interlayer resistant to hydrogen plasma etching, as demonstrated for Ti interlayer on graphite in case of DC arc jet diamond deposition [34-35].

\section{ACKNOWLEDGEMENTS}

This work was financially supported by the National Key Research and Development Program of China (Grant No. 2016YFE0201600), the National Science Fund for Distinguished Young Scholars (Grant No. 51625201), National Natural Science Foundation of China (Grant No. 51702066), International Science \& Technology Cooperation
Program of China (Grant No. 2015DFR50300), Key Laboratory of Micro-systems and Micro-structures Manufacturing, Ministry of Education, Harbin Institute of Technology (Grant No. 2016KM001), 1000 talents program, Innovative research group of NSFC 11421091. The authors would like to thank Ms. Zhang from Malvern Instruments China for the work on the laser grain size analyzer.

\section{REFERENCES}

[1] Fuentes-Fernandez E, Alcantar-Peña J, Lee G, et al. Synthesis and characterization of microcrystalline diamond to ultrananocrystalline diamond films via Hot Filament Chemical Vapor Deposition for scaling to large area applications. Thin Solid Films 2016; 603: 62-68. https://doi.org/10.1016/j.tsf.2015.11.088

[2] Tzeng Y-K, Zhang JL, Lu H, et al. Vertical-Substrate MPCVD Epitaxial Nanodiamond Growth. Nano Lett 2017; 17: 1489-1495.

https://doi.org/10.1021/acs.nanolett.6b04543

[3] Villalpando I, John P, Porro S, Wilson J. Deposition of polycrystalline and nanocrystalline diamond on graphite: effects of surface pretreatments. Appl Phys A 2017; 123: 183. https://doi.org/10.1007/s00339-017-0819-3

[4] Sussmann RS, (Ed.), CVD Diamond for Electronic Devices and Sensors, JohnWiley \& Sons, Chichester 2009.

https://doi.org/10.1002/9780470740392

[5] Aharonovich E. Neu, Diamond nanophotonics. Adv Opt Mater 2014; 2: $911-928$

https://doi.org/10.1002/adom.201400189

[6] Balmer RS, Brandon JR, Clewes CL, et al. Chemical vapour deposition synthetic diamond: materials, technology and applications. J Phys Cond Matter 2009; 21: 364221.

https://doi.org/10.1088/0953-8984/21/36/364221

[7] Voss A, Stateva SR, Reithmaier JP, Apostolova MD, Popov C Patterning of the surface termination of ultrananocrystalline diamond films for guided cell attachment and growth. Surf Coat Tech 2017; 321: 229-235.

https://doi.org/10.1016/i.surfcoat.2017.04.066

[8] Xiang D, Guo Z, Zhang L, Feng H. Preparation and cutting performance of ultra-smooth CVD composite diamond coated laddershape drilling tools. Diam Relat Mater 2018; 81: 54-60. https://doi.org/10.1016/j.diamond.2017.11.008

[9] Schwander M, Partes K. A review of diamond synthesis by CVD processes. Diam Relat Mater 2011; 20: 1287-1301.

https://doi.org/10.1016/j.diamond.2011.08.005

[10] Butler JE, Mankelevich YA, Cheesman A, Ma J, Ashfold MNR Understanding the chemical vapor deposition of diamond: recent progress. J Phys Cond Matter 2009; 21: 364201. https://doi.org/10.1088/0953-8984/21/36/364201

[11] Shin S-D, Hwang NM, Kim D-Y. High rate of diamond deposition through graphite etching in a hot filament CVD reactor. Diam Relat Mater 2002; 11: 1337-1343.

https://doi.org/10.1016/S0925-9635(01)00671-9 
[12] Yang Q, Chen W, Xiao C, Sammynaiken R, Hirose A. Synthesis of diamond films and nanotips through graphite etching. Carbon 2005; 43: $748-754$.

https://doi.org/10.1016/j.carbon.2004.10.047

[13] Yang Q, Chen W, Xiao C, Hirose A, Bradley M. Low temperature synthesis of diamond thin films through graphite etching in a microwave hydrogen plasma. Carbon 2005; 43: 2635-2638. https://doi.org/10.1016/i.carbon.2005.05.010

[14] Lu X, Yang Q, Xiao C, Hirose A. Effects of hydrogen flow rate on the growth and field electron emission characteristics of diamond thin films synthesized through graphite etching. Diam Relat Mater 2007; 16: $1623-1627$

https://doi.org/10.1016/i.diamond.2007.02.005

[15] Silva WDM, Ferreira NG, Travello J, Almeida EC, Azevedo AF, Baldan MR. Dependence of diamond nucleation and growth through graphite etching at different temperatures. Diam Relat Mater 2007; 16: $1705-1710$

https://doi.org/10.1016/i.diamond.2007.05.004

[16] Lu X, Yang Q, Xiao C, Hirose A, Tiedje T. Synthesis and field electron emission characteristics of diamond multilayer films grown by graphite etching. J Phys D Appl Phys 2007; 40: 4010.

https://doi.org/10.1088/0022-3727/40/13/015

[17] Salvadori M, Ager J III, Brown I, Krishnan K. Diamond synthesis by microwave plasma chemical vapor deposition using graphite as the carbon source. Appl Phys Lett 1991; 59: 2386-2388. https://doi.org/10.1063/1.106024

[18] Yao K, Dai B, Ralchenko V, et al. Diamond films and particles growth in hydrogen microwave plasma with graphite solid precursor: Optical emission spectroscopy study. Diam Relat Mater 2018; 82: 33-40. https://doi.org/10.1016/i.diamond.2017.12.020

[19] Tang CJ, Neves AJ, Fernandes AJS. Influence of nucleation density on film quality, growth rate and morphology of thick CVD diamond films. Diam Relat Mater 2003; 12: 1488-1494.

https://doi.org/10.1016/S0925-9635(03)00179-1

[20] Yao K, Dai B, Zhu J, et al. Diamond micropowder synthesis via graphite etching in a microwave hydrogen plasma. Powder Technol 2017; 32: 124-130. https://doi.org/10.1016/i.powtec.2017.09.021

[21] Dubray JJ, Pantano CG, Yarbrough WA. Graphite as a substrate for diamond growth. J Appl Phys 1992; 72: 3136-3142. https://doi.org/10.1063/1.351475

[22] Lambrecht WRL, Lee CH, Segall B, Angus JC, Li ZD, Sunkara M. Diamond nucleation by hydrogenation of the edges of graphitic precursors. Nature 1993; 364: 607-610. https://doi.org/10.1038/364607a0

[23] Huang $Q$, Lei $Q$, Deng $Q$, et al. Raman spectra and modulus measurement on the cross section of proton-irradiated graphite. Nuclear Instruments and Methods in Physics Research Section B: Beam Interactions with Materials and Atoms 2017; 412: 221-226. https://doi.org/10.1016/j.nimb.2017.09.004
[24] Pimenta MA, Dresselhaus G, Dresselhaus MS, Cancado LG, Jorio A Saito R. Studying disorder in graphite-based systems by Raman spectroscopy. Phys Chem Chem Phys 2007; 9: 1276-1290. https://doi.org/10.1039/B613962K

[25] Reich S, Thomsen C. Raman spectroscopy of graphite. Philosophical Transactions of the Royal Society of London A: Mathematical, Physical and Engineering Sciences 2004; 362: 2271-2288. https://doi.org/10.1098/rsta.2004.1454

[26] Poltoratskiy VG, Lavrinenko VI, Safonova MN, Petasyuk GA. A nove composite diamond-containing dispersed material of natural and synthetic diamonds powders and abrasive tools made of it. Diam Relat Mater 2016; 68: 66-70. https://doi.org/10.1016/i.diamond.2016.06.004

[27] Kanai C, Watanabe K, Takakuwa Y. Ab initio calculations on etching of graphite and diamond surfaces by atomic hydrogen. Phys Rev B 2001; 63: 235311.

https://doi.org/10.1103/PhysRevB.63.235311

[28] Vlasov I, Goovaerts E, Ralchenko V, Konov V, Khomich A, Kanzyuba M. Vibrational properties of nitrogen-doped ultrananocrystalline diamond films grown by microwave plasma CVD. Diam Relat Mater 2007; 16: 2074-2077.

https://doi.org/10.1016/j.diamond.2007.07.007

[29] Shakhov FM, Abyzov AM, Takai K Boron doped diamond synthesized from detonation nanodiamond in a $\mathrm{C}-\mathrm{O}-\mathrm{H}$ fluid at high pressure and high temperature. J Solid State Chem 2017; 256: 72-92. https://doi.org/10.1016/j.jssc.2017.08.009

[30] Reinhold-López K, Braeuer A, Romann B, Popovska-Leipertz N Leipertz A. In situ Raman monitoring of the formation and growth of carbon nanotubes via chemical vapor deposition. Procedia Engineering 2015; 102: 190-200. https://doi.org/10.1016/j.proeng.2015.01.126

[31] Harada Y, Hishinuma R, Terashima C, et al. Rapid growth of diamond and its morphology by in-liquid plasma CVD. Diam Relat Mater 2016; 63: 12-16.

https://doi.org/10.1016/i.diamond.2015.10.009

[32] Bolshakov A, Ralchenko V, Yurov V, et al. High-rate growth of single crystal diamond in microwave plasma in $\mathrm{CH}_{4} / \mathrm{H}_{2}$ and $\mathrm{CH}_{4} / \mathrm{H}_{2} / \mathrm{Ar}$ gas mixtures in presence of intensive soot formation. Diam Relat Mater 2016; 62: 49-57. https://doi.org/10.1016/i.diamond.2015.12.001

[33] Lee S-T, Lin Z, Jiang X. CVD diamond films: nucleation and growth Materials Science and Engineering: R: Reports 1999; 25: 123-154 https://doi.org/10.1016/S0927-796X(99)00003-0

[34] Guo J, Li C, Liu J, et al. Structural evolution of Ti destroyable interlayer in large-size diamond film deposition by DC arc plasma jet. Appl Surf Sci 2016; 370: 237-242.

https://doi.org/10.1016/j.apsusc.2016.02.158

[35] Guo J, Liu J, Hua C, et al. Interfacial stress evolution simulation on the graphite substrate/interlayer/diamond film during the cooling process. Diam Relat Mater 2017; 75; 12-17

https://doi.org/10.1016/i.diamond.2016.12.017

(C) 2018 Yao et al.; Licensee Lifescience Global.

This is an open access article licensed under the terms of the Creative Commons Attribution Non-Commercial License (http://creativecommons.org/licenses/by-nc/3.0/) which permits unrestricted, non-commercial use, distribution and reproduction in any medium, provided the work is properly cited. 